[Radiocarbon, Vol 22, No. 3, 1980, P 909-918]

\title{
CARBON-14 AND CARBON-13 IN SOIL $\mathrm{CO}_{2}$
}

\section{HELMUT DÖRR and KARL OTTO MÜNNICH}

\author{
Institut für Umweltphysik der Universität Heidelberg, \\ Federal Republic of Germany
}

ABSTRACT. Carbon isotope measurements in soil $\mathrm{CO}_{2}$ are presented and discussed. Soil $\mathrm{CO}_{2}$ concentration and ${ }^{13} \mathrm{C}$ profiles were measured using a new technique. A simple model describing the $\mathrm{CO}_{2}$ transport from the soil to the atmosphere is derived. The finding that $\mathrm{CO}_{2}$ in the soil is richer in ${ }^{13} \mathrm{C}$ than the $\mathrm{CO}_{2}$ leaving the soil is attributed to isotopic fractionation in molecular diffusion.

\section{INTRODUCTION}

In modeling local variations of the atmospheric $\frac{\left[{ }^{14} \mathrm{C}\right]}{\left[{ }^{12} \mathrm{C}\right]}$ ratio due to anthropogenic sources (Levin, Münnich, and Weiss, 1980) there is some doubt as to the precise value of this figure for soil respiration $\mathrm{CO}_{2}$ which considerably influences the atmospheric level. Therefore, ${ }^{14} \mathrm{C}$ soil respiration studies implemented years ago (Münnich, 1963; Münnich and Roether, 1963) have been resumed and are now being supplemented by $\mathrm{CO}_{2}$ concentration and ${ }^{13} \mathrm{C}$ profile measurements in the uppermost $60 \mathrm{~cm}$ of the soil. The findings are relevant to the understanding of soil respiration mechanisms of atmospheric $\mathrm{CO}_{2}$ balance as well as to the initial value in ${ }^{14} \mathrm{C}$ groundwater dating (Münnich, 1968; Fontes and Garnier, 1979).

\section{Theoretical considerations}

Soil $\mathrm{CO}_{2}$ is produced by respiration of plant roots and bacteriaoxidizing dead organic matter, and takes place primarily in the uppermost half-meter of the soil. If we denote $\mathrm{CO}_{2}$ production per unit soil volume and time at depth $\mathrm{z}$ by $\mathrm{q}(\mathrm{z})$ we find, for the horizontally homogeneous case in the steady state, $-(\partial j(z) / \partial z)+q(z)=0$. Since, on the time average, practically all $\mathrm{CO}_{2}$ produced leaves the soil surface at $\mathrm{z}=0$, the $\mathrm{CO}_{2}$ flux density $\mathrm{j}(\mathrm{z})$ has its maximum (negative) value at $\mathrm{z}=0$ and gradually goes to zero at greater depth $\mathrm{z}$.

It is generally assumed (de Jong and Schappert, 1972) that gas transport in the soil is primarily by diffusion. It can, in fact, be shown that "pumping" by atmospheric pressure variations only occasionally plays a role where the groundwater table is at greater depth. Turbulent motion in the atmosphere above the soil surface usually is very effectively damped out in the soil because the average momentum relaxation time $\tau$ in the soil pores is $\tau \approx \frac{\mathrm{r}^{2}}{8 \nu}$ (Münnich, 1968) giving eg, $\tau \approx 20 \mu \mathrm{sec}$ for an average pore radius of $\mathrm{r}=50 \mu$ and a kinematic viscosity $\nu=0.15$ $\mathrm{cm}^{2} / \mathrm{sec}$ for air. This means a relaxation length $\overline{\mathrm{x}}=\mathrm{v} \bullet \tau$ well below $1 \mathrm{~mm}$ for outside air motion velocity $\mathrm{v}$. It has been argued, however, (Kraner, Schroeder, and Evans, 1964) that micro-oscillation of atmospheric pressure (or rather the corresponding spatial wave pattern) might produce a kind of slight eddy diffusion in the uppermost soil layers. 


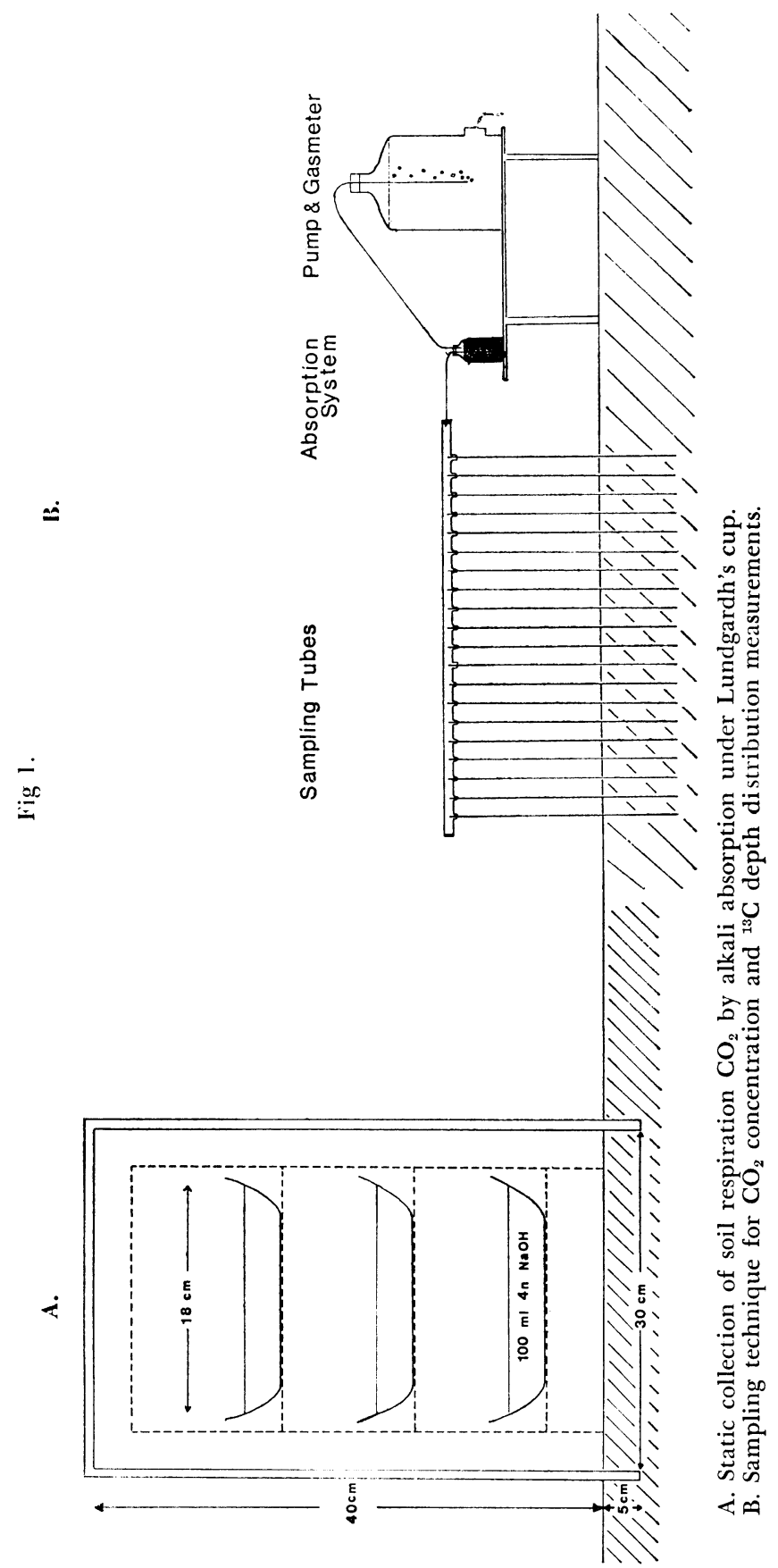




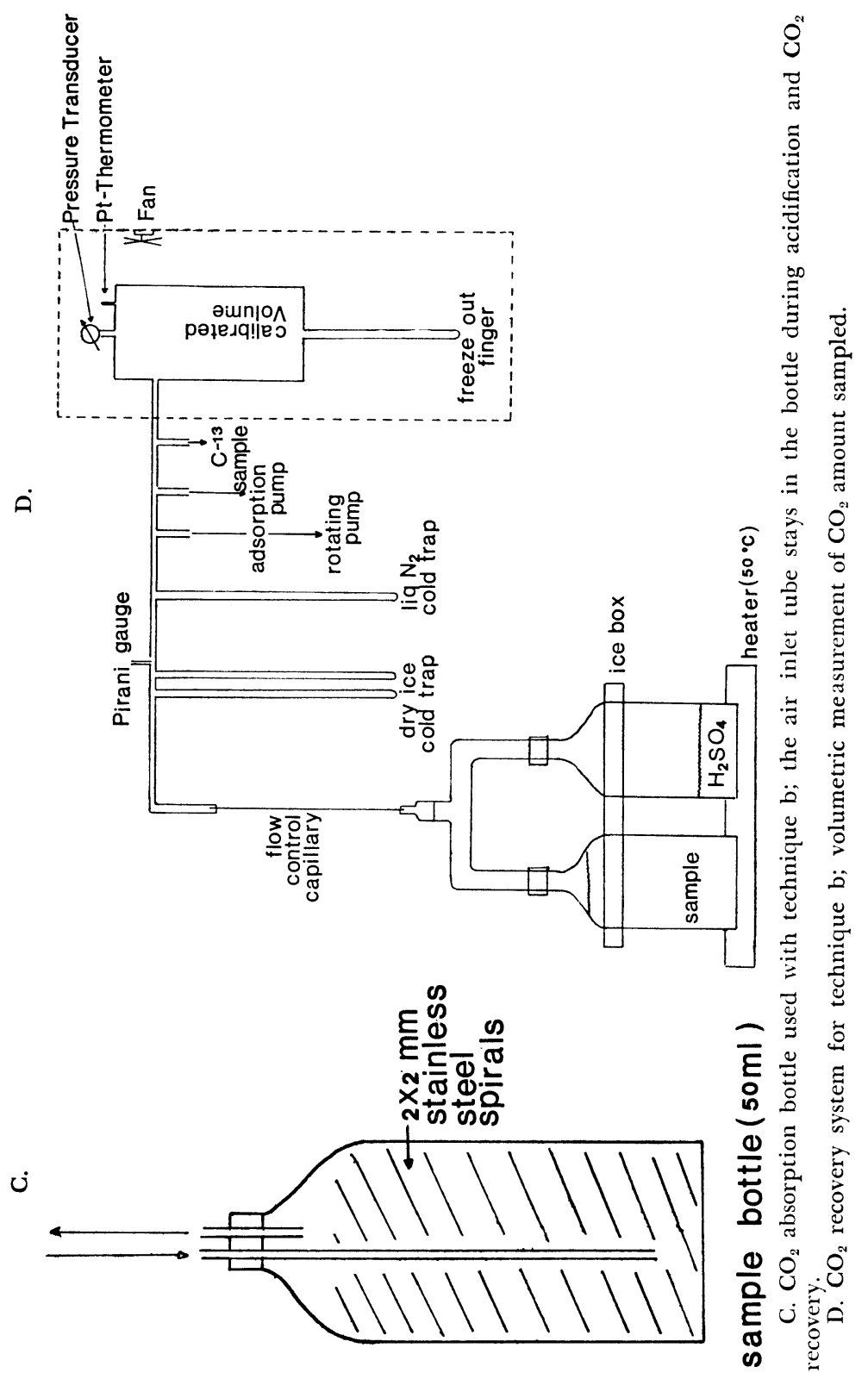


Diffusion transport of a substance through any medium is defined by its permeability ${ }^{1} \mathrm{P}=\mathrm{S} \cdot \mathrm{D}$ where $\mathrm{S}$ is the solubility, $i e$, the equilibrium partition factor of the substance between the medium in question and a reference medium; D is the diffusion constant. In our specific case the obvious reference medium is air which makes $S=\epsilon$, the air filled fraction of the total soil volume (porosity). The available (air-filled) porosity $\epsilon$ and the volumetric fraction of soil moisture, F, add up to the total porosity $\epsilon_{0}=\epsilon+\mathrm{F}$ of the soil. The diffusion constant, $\mathrm{D}$, on the other hand, would be identical to $\mathrm{D}_{0}$, the diffusion constant of $\mathrm{CO}_{2}$ in air, only if the soil consisted of a bundle of straight capillary tubes pointing in the direction of the concentration gradient. In reality, however, we have $\mathrm{D}=\beta \cdot \mathrm{D}_{0}$ with a factor $\beta \leqslant 1$, considering the fact that the reduction of available diffusion cross-section, only on the average, is given by the available porosity, $\epsilon$. Microscopically, this cross-section fluctuates around the average value, larger voids alternate with bottlenecks where the soil grains touch each other. It can easily be shown, from the extreme example of very narrow bottlenecks, that the larger than average cross-section between the two bottlenecks do not compensate their impedance to diffusion. With reference to a similar mechanism, assuming that the diffusing substance cannot travel the direct route, the factor, $\mathrm{k}=1 / \beta$, is often called the tortuosity factor (see, eg, Penman, 1940; Zimmermann, Münnich, and Roether, 1967).

\section{EXPERIMENTAL METHOD}

Figure 1A shows static collection by Lundgardh's inverted cup The $\mathrm{CO}_{2}$ diffusing out of the soil surface is collected under a tin container and absorbed quantitatively in three ceramic dishes containing a total of $300 \mathrm{ml} 4$ normal sodium-hydroxide-solution. The average sampling time is two weeks. With this method, soil respiration rate, ${ }^{13} \mathrm{C}$, and ${ }^{14} \mathrm{C}$ content of respiration $\mathrm{CO}_{22}$ are measured.

Figure $1 \mathrm{~B}$ shows $\mathrm{CO}_{2}$ and ${ }^{13} \mathrm{C}$ depth profile measurement. Twenty thin brass tubes, $70 \mathrm{~cm}$ long, of $2 \mathrm{~mm}$ outer diameter, carrying 12 inlet holes of $0.5 \mathrm{~mm}$ diameter just behind the cone tip are driven to a preset depth into the soil. All probes are connected in parallel and are attached to a $5 \mathrm{~L}$ Mariotte bottle serving as an air pump and as a gas meter, simultaneously. Soil $\mathrm{CO}_{2}$ contained in the air stream is absorbed quantitatively in a $50 \mathrm{ml}$ glass bottle. This absorption bottle contains a packing of stainless steel spirals $2 \times 2 \mathrm{~mm}$ in diameter (Vereinigte FüllkörperFabriken, D-5412 Baumbach) which holds $4 \mathrm{ml}$ of a 4 normal $\mathrm{NaOH}$ solution like a sponge exposing a very large absorption surface to the passing air (fig 1C). Total air flow rate is about $10 \mathrm{~L} / \mathrm{hr}$ (or $500 \mathrm{cc} / \mathrm{hr}$ per individual probe). At this flow rate, the natural diffusion steady state in the soil cannot be disturbed. We show this by assuming that a sphere of radius, $r$, around the suction tip had been flushed free from $\mathrm{CO}_{2}$ by

\footnotetext{
1 The permeability $P$, is often incorrectly called a diffusion constant (see eg, Kraner, Schroeder, and Evans, 1964: “bulk diffusion constant"). This notation is tolerable only if a single and homogeneous medium is to be described (see Stiller and Carmi, 1975 for the treatment of the general case).
} 
injecting $\mathrm{CO}_{2}$-free air into the soil. Relaxation time, which restores the natural situation by diffusion, can be estimated from the lowest order relaxation time, $\tau_{1}$, of the corresponding eigenfunction representation of the problem (Carslaw and Jaeger, 1959). We find $\tau_{1}=\mathrm{r}^{2} /\left(\pi^{2} \mathrm{D}\right)$ $\approx \mathrm{r}^{2} / 60[\mathrm{~min}]$, which means that the disturbance produced by injection of $1 / 2 \mathrm{~L}$ of air (with $\epsilon=0.25$ this gives $\mathrm{r}=7.8 \mathrm{~cm}$ ) decays with a relaxation time in the order of one min.

Absorbed $\mathrm{CO}_{2}$ is recovered by adding $5 \mathrm{ml}$ of 5 normal sulfuric acid to the sampling bottle (fig 1D). The sample and acid bottles are heated from the bottom and cooled from the top. The stainless steel spiral packing, thus, is continuously flushed with water vapor enhancing the degassing of the system. The whole system is cleaned of air beforehand in the same way. The transfer of $\mathrm{CO}_{2}$ to the vacuum line is again by water vapor (flux controlled by the capillary) condensing in the first cold trap while the $\mathrm{CO}_{2}$ is being collected in the second. The crucial point of our absorption and recovering technique (a continuation and simplification of the technique used by Esser, ms, for atmospheric ${ }^{13} \mathrm{C}$ work) is that there is absolutely no loss of absorbing solution, and the $\mathrm{CO}_{2}$ is recovered quantitatively afterwards. The amount of $\mathrm{CO}_{2}$ is measured volumetrically in a calibrated metal container with precision temperature and pressure meters. Using a $\mathrm{Na}_{2} \mathrm{CO}_{3}$ standard solution, the measurement of the $\mathrm{CO}_{2}$ amount sampled is reproducible to $\pm 1.2 \%$ o STD. The system allows for checking of degassing of the absorbing solution to better than $0.1 \%$ of the $\mathrm{CO}_{2}$ amount processed. The ${ }^{13} \mathrm{C}$ measurements are reproducible to $\pm 0.03 \%$. For ${ }^{14} \mathrm{C}$ measurement setup, see Schoch and others (1980).

RESULTS AND DISCUSSION

\section{$\mathrm{CO}_{2}$ soil respiration flux and temperature}

From our measurements the flux density of soil respiration $\mathrm{CO}_{2}$ supplied to the atmosphere is determined independently by two different techniques. Figure 2 shows both sets of data: the dots give the rates calculated from the concentration versus depth profiles of figure 4 as $\mathrm{j}=-\mathrm{P}(\mathrm{dc} / \mathrm{dz})$, while the histogram shows the amount of $\mathrm{CO}_{2}$ collected under the inverted cup divided by the collection time and the soil area covered by the cup. Figure 3 nicely shows how the flux depends on soil temperature, apparently being approximately doubled by each $5^{\circ} \mathrm{C}$ temperature increase. The flux density is calculated from the profiles with $\mathrm{P}=\epsilon \beta \mathrm{D}_{0}=.042 \mathrm{~cm}^{2} / \mathrm{sec}$, assuming the free porosity to be $\epsilon=.20$, and the tortuosity reduction fractor, $\beta$, by which the gas diffusion constant, $D_{0}=.15 \mathrm{~cm}^{2} / \mathrm{sec}$, is to be multiplied to be $\beta=2 / 3$ (Penman, 1940; Zimmermann, Münnich, and Roether, 1967a). In view of the uncertainty of the factors $\epsilon$ and $\beta$, the agreement between the two data sets is quite acceptable. The soil $\mathrm{CO}_{2}$ profiles have been fitted by a parabolic curve that occurs if constant $\mathrm{CO}_{2}$ production is assumed between 0 and $60 \mathrm{~cm}$ depth. Inspection shows, however, that, eg, an exponential fit, assuming exponential decrease of source strength with depth at a scale height $\overline{\mathrm{z}} \approx 60 \mathrm{~cm}$, would be, likewise, possible. 
Note that the flux variation histogram derived from $\mathrm{CO}_{2}$ absorbed under the inverted cup crosses the other curve and gives comparatively lower fluxes at high respiration intensity. This is to be expected if absorption in the alkali solution is not fast enough: the total absorbing alkali surface in our case is just about equal to the soil surface area covered by the inverted cup. Thus, if $\mathrm{CO}_{2}$ absorption were at its maximum rate (piston velocity $\mathrm{w}_{\mathrm{a}}=700 \mathrm{~cm} / \mathrm{hr}$, see Münnich, 1963) the steady state $\mathrm{CO}_{2}$ concentration under the cup would always be below atmospheric $\mathrm{CO}_{2}$ level, and the system would gain $\mathrm{CO}_{2}$ from the atmosphere. Ideally, the concentration under the cup should always be identical with the atmospheric concentration to avoid gain or loss due to diffusion

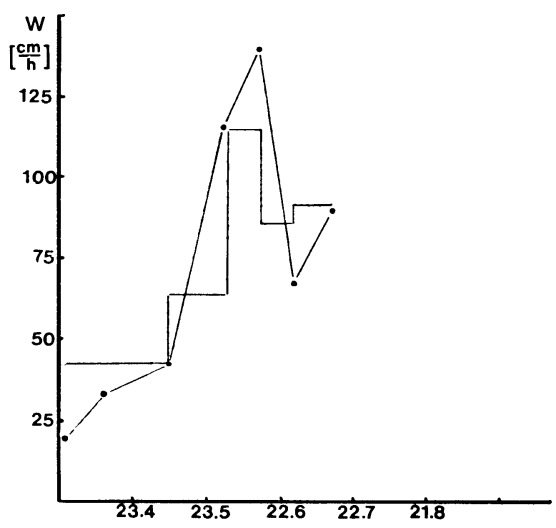

Fig 2. Soil respiration $\mathrm{CO}_{2}$ flux density $\mathrm{j}$ vs date (1979) presented as the production velocity $\mathrm{w}=\mathrm{j} / \mathrm{c}_{\mathrm{A}}$ with standard atmospheric concentration $\mathrm{c}_{\mathrm{A}}=330 \mathrm{ppm}$.

The dots are derived from measured $\mathrm{CO}_{2}$ concentration profiles (fig 4) with $\epsilon=$ $0.2 ; \beta=2 / 3 ; \mathrm{D}_{o}=0.15 \mathrm{~cm}^{2} / \mathrm{sec}$.

The histogram represents average flux density values for the time intervals indicated, measured directly by the amount of $\mathrm{CO}_{2}$ collected under an inverted cup.

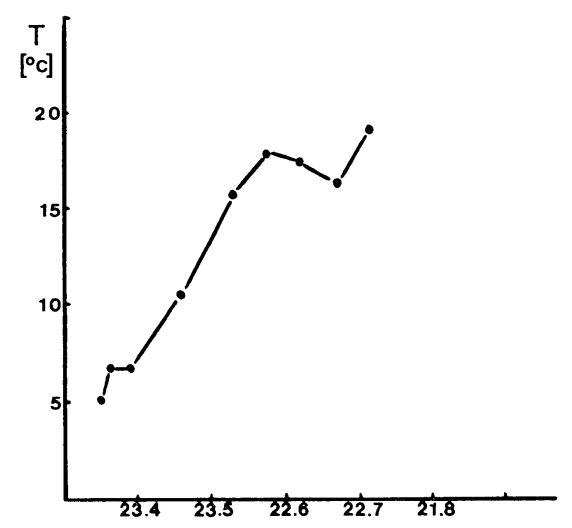

Fig 3. Soil temperature versus date (1979) at depth, $10 \mathrm{~cm}$, measured by a platinum thermometer. 
around the rim of the cup. From the data in figure 2, we might estimate that the real absorption piston velocity is about $50 \mathrm{~cm} / \mathrm{hr}$ instead of 700 . Statistically, there is a stagnant molecular diffusion layer of air over the absorber of about $10 \mathrm{~cm}$ thickness. In the future, we shall try adjusting absorption velocity by an internal fan in order to force the cup concentration to approximately atmospheric level.

${ }^{14} \mathrm{C}$. One of us measured soil respiration $\mathrm{CO}_{2}$ under an inverted cup during the period, 1958 to 1962 (Münnich, 1963; Münnich and Roether, 1963) finding that the ${ }^{14} \mathrm{C}$ level in soil respiration seemed to follow the increasing atmospheric level with a time lag of about 2 to 3 years. The present data (table 1 ) shows no significant difference in ${ }^{14} \mathrm{C}$ level of soil
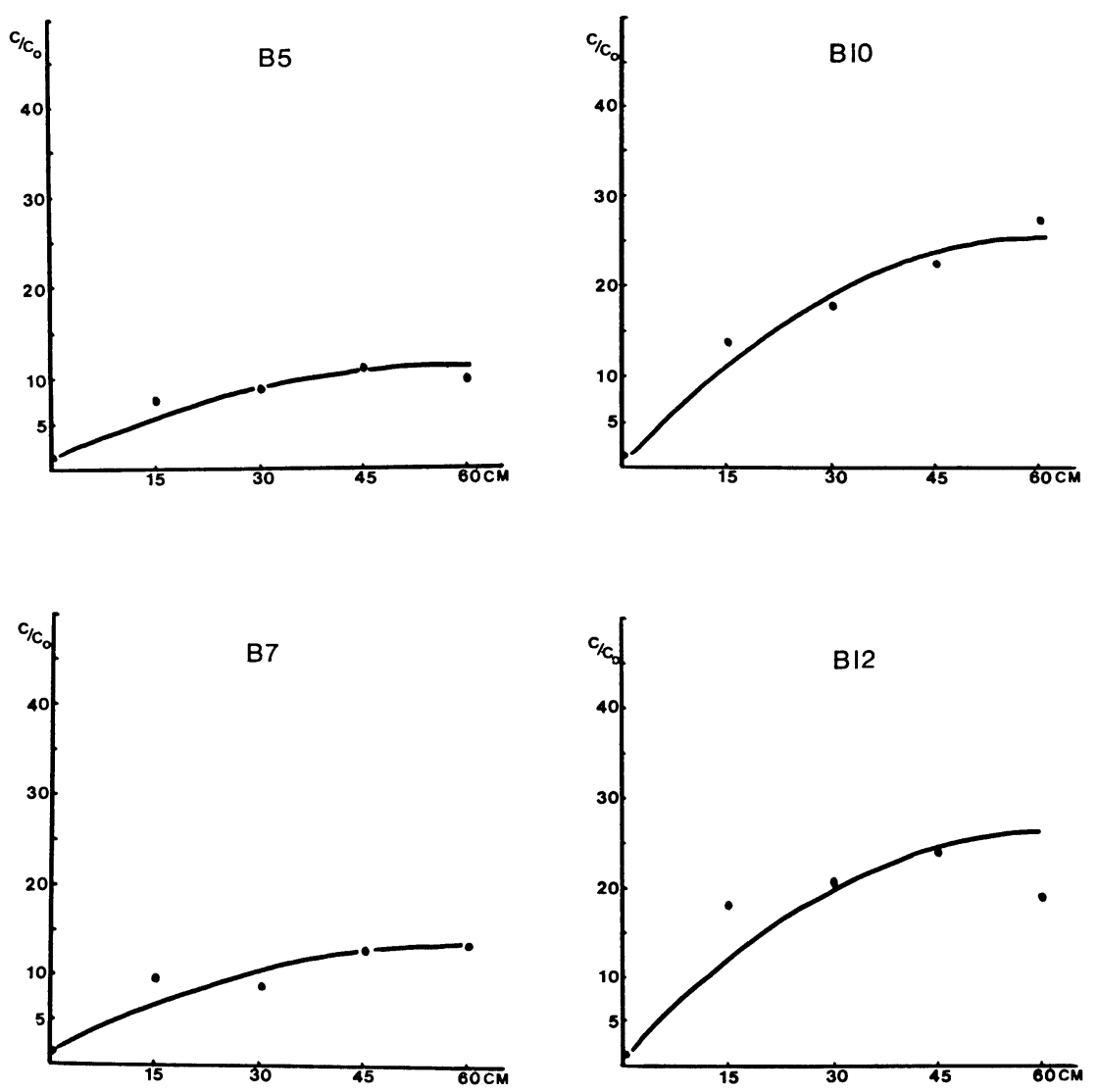

Fig 4. $\mathrm{CO}_{2}$ concentration versus depth profiles taken at the sample location of table 1. The parabolic fit to data points assumes constant $\mathrm{CO}_{2}$ production between 0 and $60 \mathrm{~cm}$ depth (see text). With this assumption and the values of fig 2 for $\epsilon, \beta$, $\mathrm{D}_{0}$ one obtains the following $\mathrm{CO}_{2}$ source densities $\mathrm{q}$ :
B5: 10 April 79;
B7: 9 May 79;
B10:26 June 79 ;
B12:11 July 79 ;
$\mathrm{q}=24 \mathrm{mmoles} \mathrm{CO}_{2} / \mathrm{m}^{3} \mathrm{hr}$
29
59
59


$\mathrm{CO}_{2}$ if compared with contemporary atmospheric levels. Although the lowermost $100 \mathrm{~m}$ of the atmosphere are strongly influenced by soil respiration $\mathrm{CO}_{2}$ (Levin, Münnich, and Weiss, 1980) the ${ }^{14} \mathrm{C}$ level in the atmospheric $\mathrm{CO}_{2}$ is obviously altered very little by this. This greatly simplifies the interpretation of man-made ${ }^{14} \mathrm{C}$ variations (Levin, Münnich, and Weiss, 1980).

${ }^{13} \mathrm{C}$. If the biospheric system under investigation is basically in a steady state, respiration $\mathrm{CO}_{2}$ derived from organic matter with $\delta^{13} \mathrm{C}=-25 \%$ o must, on the average, have $\delta^{13} \mathrm{C}=-25 \%$, as well. This, of course, does not exclude time variations around the average value. Both our flux and profile data show such variations with time. However, particularly during the time of high respiration flux, $i e$, after mid-May, $\mathrm{CO}_{2}$ in the soil is richer in ${ }^{13} \mathrm{C}$ than $\mathrm{CO}_{2}$ leaving the soil by about $3.5 \%$. This is to be expected if transport is, as generally assumed, primarily by molecular diffusion: Craig (1954) notes that the diffusion constant of ${ }^{13} \mathrm{CO}_{2}$ should be by $4 \%$ smaller than the one of ${ }^{12} \mathrm{CO}_{2}$. As in evaporation from a tree leaf (Zimmermann, Ehalt, and Münnich, 1967b), making water in the leaf heavier than water passing through it and being transpired to the atmosphere, we should find $\mathrm{CO}_{2}$ in the soil $4 \%$ heavier than that in the flux leaving the soil. No variation of the isotopic composition with depth should occur despite the strong increase of $\mathrm{CO}_{2}$ concentration with depth. This is easily verified by Fick's law, and it seems to be exactly what we observe (fig 5). This behavior has been noticed before (Fontes and Garnier, 1979), but, to our knowledge, has not been explained according to our methods.

\section{CONCLUSION}

The data presented shows that the technique used yields reliable information on soil respiration fluxes and isotopic composition. We

ТАВı 1

\begin{tabular}{rccc}
\hline Sampling time & $\begin{array}{c}\Delta^{14} \mathrm{C}(\%) \\
\text { atm CO } \mathrm{HD}_{2}\end{array}$ & $\begin{array}{c}\Delta^{14} \mathrm{C}(\%) \\
\text { soil respiration } \mathrm{CO}_{2} \mathrm{HD}\end{array}$ & $\begin{array}{c}\delta^{13} \mathrm{C}(\%) \\
\text { soil respiration } \mathrm{CO}_{2}\end{array}$ \\
\hline $16.3-30.3 .79$ & $278 \pm 5$ & & \\
$24.3-10.4 .79$ & $284 \pm 6$ & $287 \pm 6$ & \\
$2.4-12.4 .79$ & $293 \pm 6$ & & \\
$12.4-19.4 .79$ & $281 \pm 5$ & & \\
$19.4-25.4 .79$ & $285 \pm 5$ & $289 \pm 5$ & \\
$27.4-4.5 .79$ & $286 \pm 5$ & $293 \pm 5$ & -24.6 \\
$4.5-14.5 .79$ & $311 \pm 5$ & $282 \pm 5$ & -25.8 \\
$10.4-9.5 .79$ & $288 \pm 5$ & $296 \pm 5$ & -25.9 \\
$14.5-25.5 .79$ & $318 \pm 4$ & $286 \pm 5$ & -25.4 \\
$9.5-30.5 .79$ & & & -24.8 \\
$1.6-8.6 .79$ & & & \\
$30.5-13.6 .79$ & & & \\
$8.6-15.6 .79$ & & & \\
$13.6-26.6 .79$ & & & \\
$26.6-11.7 .79$ & & & \\
\hline
\end{tabular}

${ }^{14} \mathrm{C}$ and ${ }^{13} \mathrm{C}$ data on soil $\mathrm{CO}_{2}$ collected by alkali absorption under an inverted cup (sample location on uncultivated sandy soil with loess loam admixtures $15 \mathrm{~km}$ south of Heidelberg). ${ }^{14} \mathrm{C}$ data on atmospheric $\mathrm{CO}_{2}$ samples collected in Heidelberg are also given for comparison. 

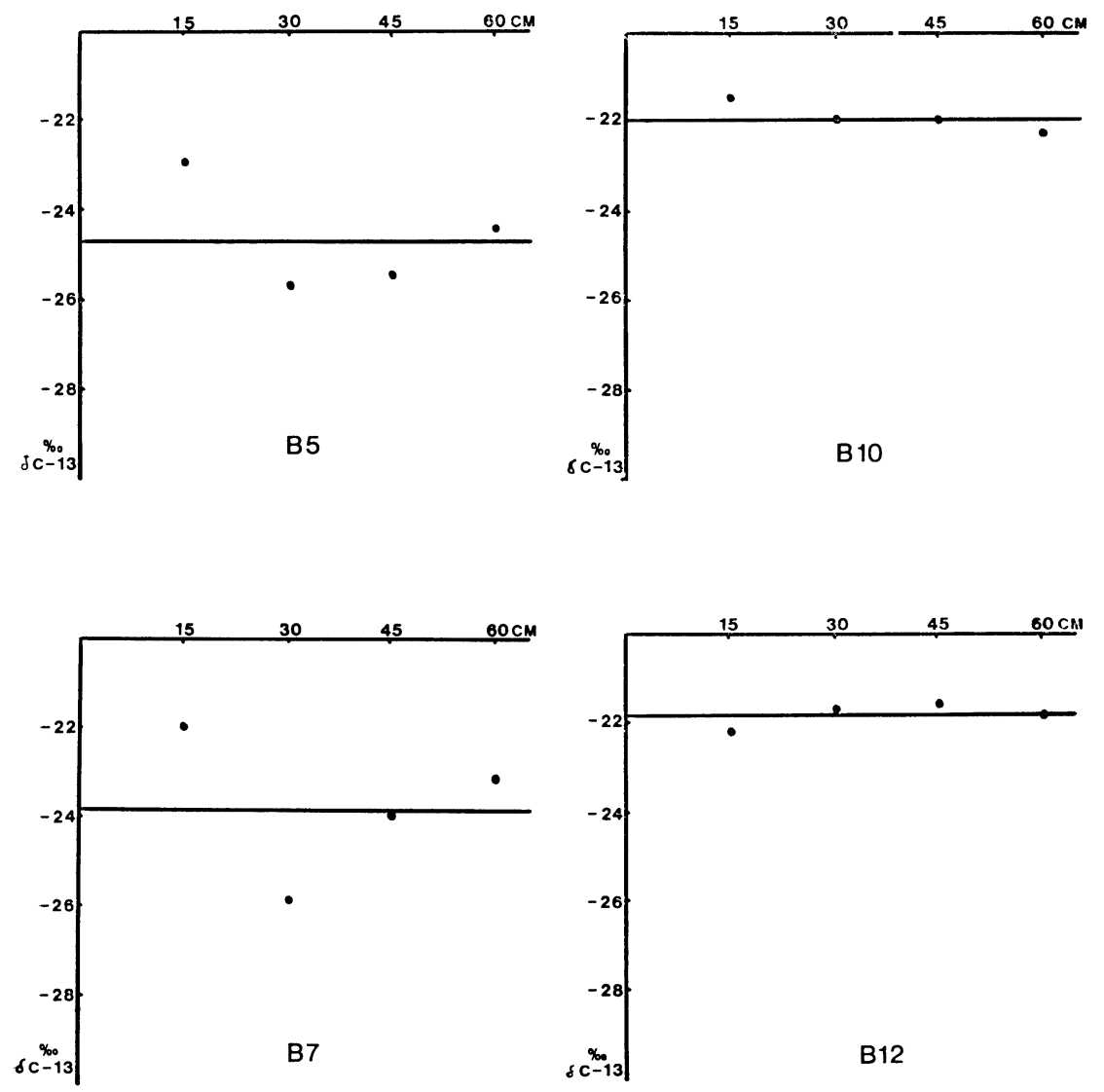

Fig 5. Soil $\delta^{13} \mathrm{C}$ profiles measured; see fig 4 for sampling dates.

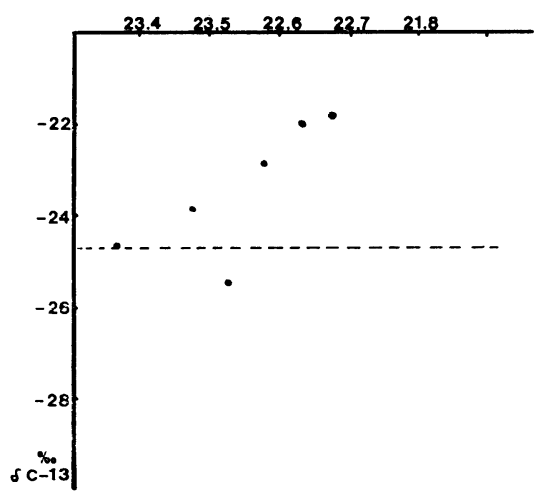

Fig 6. $\delta^{13} \mathrm{C}$ in soil $\mathrm{CO}_{2}$ versus date of sampling (average values for individual profiles). Broken line shows average isotopic composition of $\mathrm{CO}_{2}$ leaving the soil (table 1). Note that after mid-May the standing crop in the soil is heavier isotopically than $\mathrm{CO}_{2}$ in the soil respiration flux. 
shall continue these measurements in combination with radon-222 measurements in the soil using the detector designed by Roether and Kromer, (1978). Some tentative results have already been obtained (Volpp, personal commun, 1979). One of the aims of this combined study is to provide better flux data for soil-born gases to calibrate a regional atmospheric model. This will be developed to connect atmospheric concentrations with fluxes to and from the earth's surface by using meteorologic data such as atmospheric stability (Levin, Münnich, and Weiss, 1980). The study also relates to the question of initial ${ }^{14} \mathrm{C}$ content in groundwater.

REFERENCES

Carslaw, H S and Jaeger, J C, 1959, Conduction of heat in solids: Oxford, Clarendon Press, p 233.

Craig, Harmon, 1954, Carbon 13 in plants and the relationships between carbon 13 and carbon 14 variations in nature: Jour Geology, v 62, p 122.

Esser, Norbet, ms, 1975, Messung der absoluten Konzentration und des ${ }^{13} \mathrm{C}$-Gehalts von atmosphärischem $\mathrm{CO}_{2}$ : Thesis, Inst f Umweltphysik, Heidelberg.

Fontes, J C and Garnier, J M, 1979, Determination of initial ${ }^{14} \mathrm{C}$ activity of the total dissolved carbon: A review of the existing models and a new approach: Water Resources Research, v 15, no. 2, p 399-413.

de Jong, $\mathbf{E}$ and Schappert, $\mathbf{H}$ J V, 1972, Calculation of soil respiration and activity from $\mathrm{CO}_{2}$ profiles in the soil: Soil Science, v 113, p 328-333.

Kraner, H W, Schrocder, G L, and Evans, R D, 1964, Measurements of the effects of atmospheric variables on Rn-222 flux and soil-gas concentrations, in The natural radiation environment: Houston, Texas, Rice Univ Pub, p 191-215.

Levin, Ingeborg, Münnich, K O, and Weiss, Wolfgang, 1980, The effect of anthropogenic $\mathrm{CO}_{2}$ and ${ }^{14} \mathrm{C}$ sources on the distribution of ${ }^{14} \mathrm{C}$ in the atmosphere, in Stuiver, Minze and Kra, Renee, eds, Internatl radiocarbon conf, 10th, Proc: Radiocarbon, v 22, no. 2 , p 379-391.

Münnich, K O, 1963, Der Kreislauf des Radiokohlenstoffs in der Natur: Naturwiss, v 6 , p $211-213$.

1968, Isotopendatierung von Grundwasser: Naturwiss, v 55, no. 4, p 158-163.

Münnich, K O and Roether, Wolfgang, 1963, A comparison of carbon 14 ages and tritium ages of groundwater, in Radioisotopes in hydrology: Vienna, IAEA, p 397406.

Penman, H L, 1940, Gas and vapour movements in the soil: Jour Agric Science, v 30, no. 3, p 437-461.

Roether, Wolfgang and Kromer, B, Field determination of air-sea gas exchange by continuous measurements of radon-222: Pure appl Geophys, v 116, p 476-485.

Schoch, Hildegard, Bruns, Michael, Münnich, K O, and Münnich, Marianne, 1980, A multi-counter system for high precision carbon 14 measurements, in Stuiver, Minze and Kra, Renee, eds, Internatl radiocarbon conf, 10th, Proc: Radiocarbon, v 22 , no. 2 , p 442-447.

Stiller, M and Carmi, I, 1975, Water transport through Lake Kinneret sediments traced by tritium: Earth and Planctary Sci Letters, v 25, p 297-304.

Zimmermann, Uwe, Ehalt, D and Münnich, K O, 1967, Soil water movement and evotranspiration: changes in the isotopic composition of the water, in Isotopes in hydrology: Vienna, IAEA, p 567-585.

Zimmermann, Uwe, Münnich, K O, and Roether, Wolfgang, 1967, Downward measurement of soil moisture traced by means of hydrogen isotopes: Washington, D C, Am Geophys Union, mon 11, p 28-36. 